\title{
Bioactivity-guided fractionation of a methanol leaf extract from Gnetum africanum with potential anti-diabetic activity: (-)-Epicatechin as the active principle
}

\author{
Nkeiruka Emmanuela UDEH ${ }^{1, *}(\mathbb{D})$, Charles Okeke NNADI 2 (D), Aruh Otah ANAGA ${ }^{3}$ (D), \\ Isaac Uzoma ASUZU 3 iD
}

1 Department of Veterinary Biochemistry and Animal Production, College of Veterinary Medicine, Michael Okpara University of Agriculture, Umudike PMB 7267, Umuahia, Abia State, Nigeria

2 Department of Pharmaceutical and Medicinal Chemistry, University of Nigeria, Nsukka, 410001, Enugu State, Nigeria.

3 Department of Veterinary Physiology and Pharmacology, University of Nigeria, Nsukka, 410001, Enugu State, Nigeria.

* Corresponding Author. E-mail: udeh.nkeiruka@mouau.edu.ng (N.E.U.); Tel. +234 7030390379.

Received: 19 November 2020 / Revised: 03 January 2021/ Accepted: 08 January 2021

\begin{abstract}
Dietary constituents of plants such as flavonoids are very important in ameliorating the challenges of metabolic disorders such as diabetes mellitus. The study evaluated the antidiabetic activities of fractions and a known flavonoid isolated from Gnetum africanum (Welw) of fasting blood sugar (FBS) in alloxan-induced diabetic albino rats. Antidiabetic activity-guided isolation by column chromatographic (CC) separation of methanol extract and purification of the most active CC fractions by semi-preparative high performance liquid chromatograpgy (HPLC) yielded a known flavonoid (GAF7.4) and four other uncharacterized fractions. The structure of GAF7.4 was elucidated based on the 1D and 2D NMR and HREIMS spectroscopic analyses. Antidiabetic activity was conducted by alloxan-induced FBS in diabetic rats model using glibenclamide as standard. The flavonoid (GAF7.4) was identified as (-)-epicatechin. The CC fraction $7(50 \mathrm{mg} / \mathrm{kg})$ elicited significant $(\mathrm{p}<0.05)$ reduction in FBS of $42.3 \%$ after $6 \mathrm{~h}$. The isolated flavonoid (GAF7.4), $10 \mathrm{mg} / \mathrm{kg}$ dose caused a significantly higher reduction in FBS of $71.4 \%$ in alloxan induced diabetic rats compared with $41.2 \%$ reduction in glibenclamide $(2 \mathrm{mg} / \mathrm{kg})$ control. This represented the first report of epicatechin in G. africanum and our findings have contributed new knowledge to antidiabetic constitutents of the plants.
\end{abstract}

KEYWORDS: Gnetum africanum; alloxan; fasting blood sugar; (-)-epicatechin; antidiabetic.

\section{INTRODUCTION}

Diabetes mellitus is one of the top causes of mortality in adults with global health expenditure estimated to be USD 727 billion [1]. The international diabetes federation report showed that 285 million people had diabetes in 2009 which had climbed astronomically to 425 and 463 million in 2017 and 2019 respectively [2]. The rising trends have been attributed to ageing, increase in urbanization and obesogenic environments especially in type 2 diabetes [3]. However, this number is expected to increase to 578 million $(10.2 \%)$ in 2030 and 700 million (10.9\% of the global adult population of 20-79 years) in 2045 [4]. The increase of diabetes prevalence with age leads to a prevalence of 19.9\% (111.2 million) in people aged 65-79 years. Currently, half $(50.1 \%)$ of the people with diabetes do not know that they have diabetes and as an important public health problem, several preventive measures have been adopted [4]. Consequently, different approaches have been developed for the treatment of diabetes, like insulin in type I diabetes and oral hypoglycemic agents such as sulphonylureas, biguanides, thiazaolidinediones, meglitinides and alphaglucosidase inhibitors [5]. These synthetic drugs are costly and replete with side effects [6, 7]. The search for safe alternatives is therefore, a priority and plants-based products are potential sources.

Gnetum africanum (family Gnetaceae) is a dioecious liana which grows mainly in the wild in Central and West Africa and the leaves have important economic, culinary and medical uses [8]. It is an edible plant

How to cite this article: Udeh NE, Nnadi CO, Anaga AO, Asuzu IU. Bioctivity-guided fractionation of a methanol leaf extract from Gnetum africanum with potential anti-diabetic activity: (-)-Epicatechin as the active principle. J Res Pharm. 2021; 25(1): 72-79. 
widely used in West Africa as a vegetable. It is relevant in ethnomedicine in Nigeria for the treatment of diabetes, piles, high blood pressure, sore throats and enlarged spleen [8, 9]. Recent studies have established antidiabetic and antidyslipidaemic as well as protective effects of G. africanum on rat pancreatic islets [10-12]. However, no active principle has hitherto been isolated from the plant with these bioactivities.

In this study, Gnetum africanum leaf extract, a safe [12] and readily available anti-diabetic plant used in folkloric medicine, was subjected to antidiabetic activity-guided fractionation on alloxan-induced diabetic Wistar rats. Antidiabetic activity of the crude methanol extract has been scientifically validated [10], however, no active compound has been hitherto, identified to possess such activity. In this paper, we report the isolation, characterization and biological activity of the major antidiabetic principle of G. africanum.

\section{RESULTS}

\subsection{Phytochemical constituents of G. africanum}

Qualitative phytochemical screening of the methanol extract showed the presence of flavonoids, alkaloids, saponins, terpenes, tannins, glycosides and carbohydrates (starch and reducing sugars). Polyuronoids were absent.

\subsection{Bioactivity-guided isolation of epicatechin}

CC fractionation of the crude methanolic leaf extract of G. africanum yielded 10 fractions (GAF1GAF10). The fractions were identified by thin layer chromatographic analysis of collected eluates. Further separation and purification of GAF7 furnished one pure compound and four other uncharacterized fractions.

\subsection{Characterization of isolated compound}

The purified isolate GAF7.4 was a white crystalline substance was isolated ( $\mathrm{UV}_{\max } 220 \mathrm{~nm}$ ). The +ESIMS spectrum returned a quasi-molecular ion at $m / z 291.1743[\mathrm{M}+\mathrm{H}]^{+}, \mathrm{tR}=3.701 \mathrm{~min}$, (Figure 1) with elemental formula $\mathrm{C}_{15} \mathrm{H}_{14} \mathrm{O}_{6}$ (calculated for $\mathrm{C}_{15} \mathrm{H}_{15} \mathrm{O}_{6}$ : 291.2760 Da).Rf $0.27 \quad\left(\mathrm{CHCl}_{3}\right.$ : EtOAc: $\mathrm{MeOH}$ $(0.5: 3.0: 2.0))$. The chemical structure of the identified compound is shown as insert in the Figure 1.

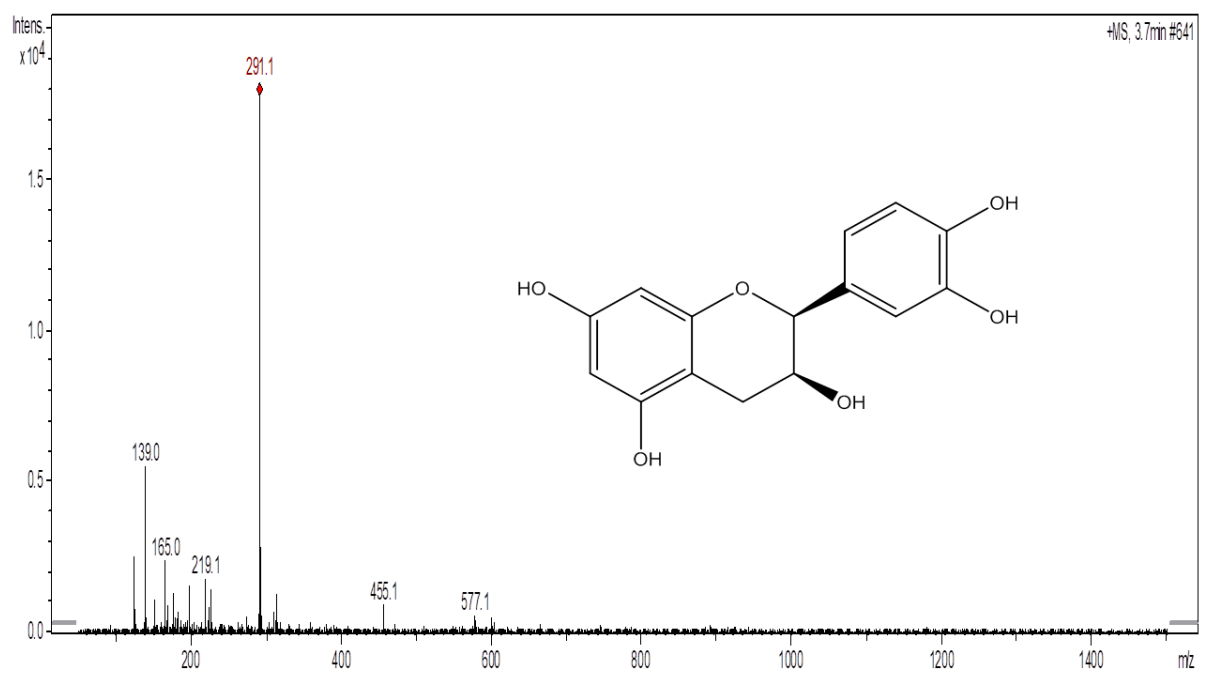

Figure 1.HPLC-MS compound spectra of isolated compound (retention time $3.701 \mathrm{~min}$ )

The ${ }^{1} \mathrm{H}$ NMR spectrum of GAF7.4 (Table 1 and Figure S1) showed the presence of a methylene proton, $\delta 2.87$ and $2.75 \mathrm{ppm}$, in close proximity to electronegative centres and strongly coupled to the proton $\delta 4.17$ $\mathrm{ppm}$. The presence of signals at $\delta$ 5-7 ppm suggests the presence of aromatic protons at different positions. The ${ }^{13} \mathrm{C}$ NMR spectrum (Table 1 and Figure S2) showed all the 15 carbons and the presence of aromatic ring was confirmed by the resonance of C-1'-6' ( $\delta 115.3-145.8 \mathrm{ppm})$ and C-5-10 ( $\delta$ 95.9-157.9 ppm). The only methylene signal was assigned from the resonance at $\delta 29.2 \mathrm{ppm}$ which was further confirmed from the HSQC spectrum (Table 1, Figure S3). Other carbon signals were assigned from the HSQC which confirmed the presence of 1 methylene $\left(\mathrm{CH}_{2}\right), 7$ methine $(-\mathrm{CH})$ and 7 quartenary $(-\mathrm{C}-)$ carbon atoms from the cross peak correlations. The methylene proton signal at $\delta 2.87$ and $2.75 \mathrm{ppm}$ cross-correlated with each other $\left(J_{\mathrm{H}-4 \mathrm{a}-\mathrm{H}-4 \mathrm{~b}}\right.$ 16.7 and $16.8 \mathrm{~Hz}$ ) and with the proton at $\delta 4.17 \mathrm{ppm}$ in the COSY spectrum (Table 1 and Figure S4), 
indicating that a hydroxyl group is present at C-3. Similarly, proton at $\delta 4.82$ cross-correlated with proton at $\delta 4.17 \mathrm{ppm}$ and its position at C-2 was further confirmed by its HMBC correlations with $\mathrm{C}-1^{\prime}, 2^{\prime}, 6^{\prime}, 3$ and 4 . Other cross peaks and correlations are shown in Table 4 and Figure S5.

Table 1. Spectral data of compound [(-)-epicatechin] isolated from G. africanum

\begin{tabular}{cccc}
\hline Carbon & ${ }^{13} \mathrm{C}, \delta(\mathrm{ppm})$ & $1 \mathrm{H}, \delta, \mathrm{ppm}(\mathrm{mult} ., \mathrm{J}(\mathrm{Hz}))$ & HSQC \\
\hline 2 & 79.8 & $4.82,1 \mathrm{H}, d, 3.7$ & $-\mathrm{CH}-$ \\
3 & 67.4 & $4.17,1 \mathrm{H}, d d d, 4.5,3.1,4.0$ & $-\mathrm{CH}-$ \\
4 & 29.2 & $2.87,1 \mathrm{H}, d d, 16.7,4.6$ & $-\mathrm{CH}_{2}-$ \\
5 & 157.6 & $2.75,1 \mathrm{H}, d d, 16.8,2.8$ & $-\mathrm{C}-$ \\
6 & 96.4 & - & $-\mathrm{CH}-$ \\
7 & 157.9 & $5.96,1 \mathrm{H}, d, 2.3$ & $-\mathrm{C}-$ \\
8 & 95.9 & - & $-\mathrm{CH}-$ \\
9 & 157.3 & $5.94,1 \mathrm{H}, d, 2.4$ & $-\mathrm{C}-$ \\
10 & 100.0 & - & $-\mathrm{C}-$ \\
$1^{\prime}$ & 132.2 & - & $-\mathrm{C}-$ \\
$2^{\prime}$ & 115.3 & - & $-\mathrm{CH}-$ \\
$3^{\prime}$ & 145.7 & $6.99,1 \mathrm{H}, d, 2.0$ & $-\mathrm{C}-$ \\
$4^{\prime}$ & 145.8 & - & $-\mathrm{C}-$ \\
$5^{\prime}$ & 115.9 & - & $-\mathrm{CH}-$ \\
$6^{\prime}$ & 119.4 & $6.77,1 \mathrm{H}, d, 8.2$ & $-\mathrm{CH}-$ \\
\hline
\end{tabular}

\subsection{Antidiabetic activity of $\mathrm{CC}$ fractions and isolated compound}

The isolation of GAF7.4 followed antidiabetic activity-guided protocol. Of the $10 \mathrm{CC}$ fractions, antidiabetic study of the fractions showed that fraction 7 (GAF7) showed the highest reduction in FBS of 42.3 $\%$ after $6 \mathrm{~h}$. This effect was comparable to that of the standard drug, glibenclamide (Table 2). This fraction was subjected to further fractionation.

Table 2. Effect of CC fractions on FBS of alloxan-induced diabetic rats.

\begin{tabular}{ccccc}
\hline \multirow{2}{*}{ Treatment/dose (mg/kg) } & \multicolumn{5}{c}{ FBS reduction $(\%)$} \\
\cline { 2 - 5 } & $1 \mathrm{~h}$ & $3 \mathrm{~h}$ & $6 \mathrm{~h}$ & $24 \mathrm{~h}$ \\
\hline Tween 20 (5 ml/kg) & $-19.0 \pm-0.1$ & $-11.0 \pm-0.2$ & $-9.0 \pm-0.2$ & $-8.0 \pm-0.1$ \\
GAF1 (50) & $19.4 \pm 0.8$ & $15.6 \pm 0.9$ & $14.5 \pm 0.9$ & $13.5 \pm 0.9$ \\
GAF2 (50) & $6.5 \pm 0.1$ & $1.9 \pm 0.2$ & $-1.2 \pm-0.1$ & $1.5 \pm 0.1$ \\
GAF3 (50) & $2.4 \pm 0.3$ & $18.2 \pm 0.6$ & $19.1 \pm 0.7$ & $11.7 \pm 0.2$ \\
GAF4 (50) & $-5.6 \pm 0.4$ & $1.1 \pm 0.7$ & $13.2 \pm 0.5$ & $7.4 \pm 0.1$ \\
GAF5 (50) & $37.4 \pm 0.2$ & $35.6 \pm 0.4$ & $42.0 \pm 0.9^{*}$ & $29.4 \pm . .6$ \\
GAF6 (50) & $6.8 \pm 0.3$ & $37.1 \pm 0.7$ & $28.9 \pm 0.2$ & $20.3 \pm 0.5$ \\
GAF7 (50) & $34.1 \pm 0.5$ & $38.3 \pm 0.7^{*}$ & $42.3 \pm 1.1^{*}$ & $23.1 \pm 0.3$ \\
GAF8 (50) & $26.3 \pm 0.4$ & $26.0 \pm 0.2$ & $21.8 \pm 0.5$ & $11.0 \pm 0.7$ \\
GAF9 (50) & $29.6 \pm 0.1$ & $30.4 \pm 0.1$ & $34.7 \pm 0.9$ & $28.6 \pm 0.2$ \\
GAF10 (50) & $10.9 \pm 0.7$ & $18.6 \pm 0.2$ & $20.0 \pm 0.2$ & $34.7 \pm 0.5^{*}$ \\
Glibenclamide $(2)$ & $30.3 \pm 0.8$ & $46.9 \pm 0.1$ & $41.2 \pm 0.4$ & $42.4 \pm 0.2$ \\
\hline ressed as mean $\pm S E M, \mathrm{n}=5,{ }^{*} \mathrm{p}<0.05$ was considered as significant when compared with control
\end{tabular}

Further separation by preparative HPLC yielded pure compound (GAF7.4) and four uncharacterized fractions. At the $6^{\text {th }}$ hour, sub-fractions GAF7.1, GAF7.2 and GAF7.4 caused 38.4, 38.4 and $71.4 \%$ reductions in FBS respectively. GAF7.3 and GAF7.5 did not elicite any significant reduction in FBS in alloxan-induced diabetic rats when compared with the controls. GAF7.1, GAF7.2, GAF7.3 and GAF7.5 were not further purified due to low or no reduction in the FBS of alloxan-induced diabetic rats as shown in Table 3. 


\section{DISCUSSION}

Phytochemical analysis on the methanol crude extract of G. africanum showed the presence of flavonoids. Although not quanitified here, several studies [13-15] had reported presence of flavonoids in the plant,with methanol, ethanol and water extracts of G. africanum having $1.04,0.35$ and $0.33 \%$ flavonoid contents respectively. The stereochemistry of GAF7.4 was determined by considering the coupling constants $\left({ }^{3} J\right)$ between $\mathrm{H}-2$ and $\mathrm{H}-3$ at C-2 and C-3. Specifically, the low observed $J_{2,3}(<5 \mathrm{~Hz})$ ruled out the 2-3-trans orientation of $\mathrm{H}-2$ and $\mathrm{H}-3$ of (-)-catechin and (+)-catechin previously reported [16]. When spectral data and coupling constants were compared with the literature, slight differences were recorded. However, (-)epicatechin has been reported for a similar compound, derived from Combretum racemosum leaves, and is an enantiomer of (+)-epicatechin [17]. More over, other literature data unequivocally assigned similar compound from Trichilia emetica seed as (-)-epicatechin on the basis of a small value for coupling $(J<1 \mathrm{~Hz})$ between the H-2 and H-3 protons, which appeared as a broad singlet at H-2, with $\delta 4.83$ ppm [18-20]. On this basis, the coupling $(J=3.7 \mathrm{~Hz})$ recorded for $\mathrm{H}-2$ and $\mathrm{H}-3$ in the compound from F7.4 differed completely from those reported for ( \pm -catechin [16] and (-)-epicatechin [17-20], confirming the 2,3 cis-orientation [21], but with a H-C-C-H dihedral angle close to $0^{\circ}$. This supports previous findings reported for $( \pm)$-epicatechin, on which basis, compound from sub-fraction GAF7.4 could be assigned (-)-epicatechin [(2R,3R)-2-(3,4dihydroxyphenyl)-3,4-dihydro-2H-chromene-3,5,7-triol] [22, 23]. The resolution of the stereochemistry of flavonoids is very important because antidiabetic activity of flavonoids depends on the chemical criterion (C-2-C-3 double bond and the ketonic group at C-4 position on ring B) which is fundamental for the bioactivity of poly-phenol compounds [24]

Table 3. Effect of isolated compound on FBS of alloxan-induced diabetic rats.

\begin{tabular}{|c|c|c|c|c|c|}
\hline \multirow{2}{*}{ Treatment/dose (mg/kg) } & \multirow{2}{*}{ Yield (mg) } & \multirow{2}{*}{ Rf } & \multicolumn{3}{|c|}{ FBS reduction $(\%)$} \\
\hline & & & $1 \mathrm{~h}$ & $3 \mathrm{~h}$ & $6 \mathrm{~h}$ \\
\hline Distilled water (5 ml/kg) & - & - & $-19.0 \pm-0.2$ & $-11.0 \pm-0.4$ & $-9.0 \pm-0,1$ \\
\hline GAF7.1 (10) & 12.3 & 0.53 & $12.0 \pm 0.2$ & $25.0 \pm 0.7$ & $38.0 \pm 1.1^{*}$ \\
\hline GAF7.2 (10) & 9.9 & 0.42 & $13.8 \pm 0.4$ & $25.0 \pm 0.8$ & $38.0 \pm 1.0^{*}$ \\
\hline GAF7.3 (10) & 46.3 & 0.38 & $-7.6 \pm 0.1$ & $-8.6 \pm-0.1$ & $6.6 \pm 0.2$ \\
\hline GAF7.4 (10) [(-)-epicatechin] & 34.5 & 0.27 & $25.0 \pm 0.3^{*}$ & $49.0 \pm 0.9^{*}$ & $71.4 \pm 1.8^{*}$ \\
\hline GAF7.5 (10) & 39.1 & 0.23 & $-20.0 \pm 0.2$ & $-23.0 \pm-0.2$ & $-13.8 \pm-0.3$ \\
\hline Glibenclamide (2.0) & - & - & $30.3 \pm 0.9$ & $46.9 \pm 1.2$ & $41.2 \pm 1.0$ \\
\hline
\end{tabular}

Data expressed as mean \pm SEM, $n=5,{ }^{*} p<0.05$ was considered as significant when compared with control

Polyphenolic compounds in plants, especially flavonoids, are among the classes of compounds that have known anti-diabetic activities [25].Gnetum africanum leaves have been reported to contain about $1.04 \%$ flavonoids in methanolic extract [13], $0.33 \%$ in aqueous extract and $0.35 \%$ in ethanolic extract [15]. Notwithstanding earlier reports of flavonoid constituents of G. africanum, this finding is the first ever report of its (-)-epicatechin content. Epicatechin is a flavan-3-ol flavonoid, which is an intermediate in the synthesis of flavonoids. Flavonoids are known to regulate glucose levels by various mechanisms. These mechanisms have been proven in all classes of flavonoids, including flavanols such as enhancing insulin secretion via regeneration of pancreatic $\beta$-cells, enhancing insulin mediated glucose uptake by target cells, inhibiting of aldose reductase, increasing $\mathrm{Ca}^{2+}$ uptake and antioxidant activity [26]. Flavonoids from Morus indicahave been implicated to increase of glucose transporter 4 (GLUT-4) expressions in the skeletal muscle of experimental rats [27]. This suggests that $M$. indica flavonoids may ameliorate hyperlipidemia and hyperglycemia engendered by high fat diet. Also, flavonoids like hesperidin, quercetin, rutin and naringenin have been reported to reduce hyperlipidemia and hyperglycemia by partly regulating fatty acid and cholesterol metabolism and affecting gene expression of glucose-regulating enzymes in diabetic animals [28]. Specifically, (-)-epicatechin present in berries are known ro improve insulin resistance, upregulated GLUT4 and decreased the hyperglycaemic condition in obese and diabetic mice.

Following the studies on Pterocarpus marsupium, it was shown that epicatechin and catechin flavonoids have anti-diabetic properties [29]. Further investigations reported some preliminary data on the favorable effects of epicatechin on glycaemic homeostasis, lipid profile and systemic inflammation [30]and that consumption of epicatechin-rich green tea could lead to reduced glucose and oral testing insulin values, as well as reduced glucose and fasting insulin concentration. Studies on Gnetum africanum showed that the crude extract caused significant reductions in blood glucose levels of diabetic rats [10] and reversed alloxan- 
induced destruction of the pancreatic islet cells [11,31]. Its safety has also been established in Wistar rats following acute and sub-chronic studies (12). Like other flavanols, (-)-epicatechin are known to prevents oxidation and covalentmodifications caused by free radicals in proteins,improve the plasma insulin and antioxidant levels in diabetic rats and alsosignificantly decreased the levels of blood glucose, HbA1c [29, 30].

\section{CONCLUSION}

Bioactivity-guided fractionation of Gnetum africanum methanolic leaf extract indicated (-)-epicatechin in sub-fraction GAF7.4. This is the first time that (-)-epicatechin is isolated from G. africanum. Its potential antidiabetic activity and previously reported safety margin makes it a potential therapeutic lead in production of new anti-diabetic agents for the management of diabetes mellitus.

\section{MATERIALS AND METHODS}

\subsection{Materials}

\subsubsection{Chemicals and regeants}

Methanol , ethylacetate, chloroform and petroleum ether, silica gel, $p$-anisaldehyde and sulfuric acid were sourced from Merck KGaA (Germany), glibenclamide from GNC (Nigeria), millipore water for HPLC and LC/ESI-MS measurement LCMS grade HiPerSolv CHROMANORM® (VWR Chemicals, Belgium).

\subsubsection{Plant material}

Gnetum africanum leaves were sourced from its natural habitat in Orba, Nsukka, Nigeria in November 2014, authenticated by a plant taxonomist. Plant specimen with voucher number, MOUAU/VPP/2014/017 was deposited in the herbarium of the Department of Veterinary Physiology and Pharmacology, Michael Okpara University of Agriculture, Umudike.

\subsubsection{Experimental animals}

Mature male albino rats $(123.5 \pm 26.5 \mathrm{~g})$ bred in the laboratory Animal Units of the Faculties of Veterinary Medicine and Pharmaceutical Sciences, University of Nigeria, Nsukka, Nigeria, were used for the experiments. They were housed in an environment of normal ambient temperature $\left(25-27{ }^{\circ} \mathrm{C}\right)$ and the lighting period was about $12 \mathrm{~h}$ daily with relative humidity of $40-60 \%$. The rats were kept in stainless steel cages, supplied with clean drinking water and fed ad libitum with standard commercial pelleted feed (Vital®) feed, Nigeria). Permission to use animals for this study was obtained from the College of Veterinary Medicine, Michael Okpara University of Agriculture, Umudike Ethics Committee guidelines on handling of laboratory animals in accordance with "Principles of Laboratory Animal Care" (NIH publication no. 85-23, revised 1985) and/or the declaration of Helsinki promulgated in 1964 as amended in 1996. (MOUAU/CVM/REC/202011).

\subsection{Methods}

\subsubsection{Extraction of plant material}

The powdered plant material $(2 \mathrm{~kg}$ ) was extracted by cold maceration in $80 \%$ methanol for $48 \mathrm{~h}$ with intermittent shaking at 2-h intervals after which they were filtered through Whatman ${ }^{\circledR}$ No. 1 filter paper. The filtrate was then concentrated invacuo using rotary evaporator (Rotavapor®, Büchi Labortechnik AG, Switzerland) connected to a cold water circulator and a pressure pump at $40{ }^{\circ} \mathrm{C}$ and 21000 pa and stored at 4 ${ }^{\circ} \mathrm{C}$ as methanol extract.

\subsubsection{Preliminary phytochemical screening}

The methanol extract of G. africanum was subjected to qualitative phytochemical screening using standard methods [32]; for identification of various classes of active chemical constitients, including alkaloids, saponins, terpenes, flavonoids, tannins and polyuronoids.

\subsubsection{Column chromatographic separation of crude methanol extract}

The extract $(10 \mathrm{~g})$ was dissolved in methanol and mixed with $40 \mathrm{~g}$ of silica gel $\left(\mathrm{F}_{254}\right)(1: 4)$ and the mixture was dried in a hot air oven. The powder was carefully layered on top of the packed silica gel $\left(\mathrm{F}_{254}\right.$, 60G, particle size $63-200 \mu \mathrm{m} / 70-230$ mesh) slurry packed column $(16 \mathrm{~cm})$ to form an even meniscus. It was covered with glass wool to avoid spattering of the eluent on the extract which may affect the separation 
process. The extract was eluted with mobile phase gradients of $100 \%$ petroleum ether, $90 \%$ petroleum ether + $10 \%$ EtOAc to $100 \%$ EtOAc, $95 \%$ EtOAc + $5 \% \mathrm{MeOH}$ to $10 \% \mathrm{MeOH}$. The mobile phase solvent was constituted as follows: $500 \mathrm{~mL}$ of $100 \%$ petroleum ether, followed by $500 \mathrm{~mL}$ each of 9:1, 8:2, 7:3, 6:4, 5:5, 4:6, 3:7, 2:8 and 1:9 of petroleum ether-EtOAc mixture, $500 \mathrm{~mL}$ of $100 \%$ EtOAc, $500 \mathrm{~mL}$ each of 9.5:0.5, 9:1 of EtOAc-MeOH mixture and finally $100 \% \mathrm{MeOH}$. The eluates $(10 \mathrm{~mL}$ each) obtained at a constant flow rate of $1 \mathrm{ml} /$ min were analyzed by thin-layer chromatography (TLC) at predetermined intervals.

\subsubsection{Analytical thin-layer chromatography of fractions}

Pre-coated silica gel $60 \mathrm{~F}_{254}$ plates, $20 \times 10 \mathrm{~cm}$ (Merck KgaA, Darmstadt) and solvent system consisting of $\mathrm{CHCl}_{3}$, EtOAc and $\mathrm{MeOH}$ (3:2:0.5) was used to pool the eluents from column chromatography into fractions based on $R_{\mathrm{f}}$ values, The plates were viewed under UV light at 254/365 nm. Bands were further detected by spraying with anisaldehyde-sulphuric acid detecting agent. The fractions obtained by CC fractionation were pooled into 10 (GAF1-GAF10) fractions and screened for anti-diabetic activity.

\subsubsection{Preparative HPLC Isolation of antidiabetic principle}

The active CC fraction, GAF7 was subjected to semi-preparative HPLC separations using a 10-cm column packed with Europrep C18-reverse phase $(20-45 \mu \mathrm{m}, 5 \mathrm{~g})$. Separation was performed under low pressure, connecting the column to a glass chamber provided with vacuum control. The mobile phase for the semi preparative separations consisted of $\mathrm{H}_{2} \mathrm{O}(\mathrm{A})$ and $\mathrm{MeOH}(\mathrm{B})$ in gradient condition: $20-100 \%$ of $\mathrm{B}$ (20 $\mathrm{min}), 100 \%$ of $\mathrm{B}(10 \mathrm{~min})$ and $20 \mathrm{~min}$ to return to initial conditions. The purification was undertaken with $500 \mu \mathrm{L}$ injection volume and flow rate was $8 \mathrm{ml} \mathrm{min}^{-1}$ at $30-35^{\circ} \mathrm{C}$.

\subsubsection{Mass Spectrophotometric (MS) measurement}

GAF7.4 was dissolved in $\mathrm{MeOH}$ at a concentration of $1 \mathrm{mg} / \mathrm{mL}$ and analyzed using UHPLC/ESIQTOF MS/MS. The detailed profiles were obtained that consisted of reproducible retention data and exact mass. Chromatographic separations were performed on a Dionex Ultimate 3000 RS Liquid Chromatography System with a Dionex Acclaim RSLC 120, C18 column $(2.1 \times 100 \mathrm{~mm}, 2.2 \mu \mathrm{m})$ using a binary gradient (A: water with $0.1 \%$ formic acid; B: acetonitrile with $0.1 \%$ formic acid) at $0.8 \mathrm{~mL} / \mathrm{min}: 0$ to $9.5 \mathrm{~min}$ : linear from $5 \%$ B to $100 \%$ B; 9.5 to $12.5 \mathrm{~min}$ : isocratic $100 \% \mathrm{~B} ; 12.5$ to $12.6 \mathrm{~min}$ : linear from $100 \%$ B to $5 \% \mathrm{~B} ; 12.6$ to $15 \mathrm{~min}$ : isocratic $5 \%$ B. The injection volume was $5 \mu \mathrm{L}$. Eluted compound was detected using a Dionex Ultimate DAD-3000 RS over a wavelength range of $200-400 \mathrm{~nm}$ and a Bruker Daltonics micrOTOF-QII quadrupole/time-of-flight mass spectrometer equipped with an Apollo electrospray ionization source in positive mode at $5 \mathrm{~Hz}$ over a mass range of $\mathrm{m} / \mathrm{z}$ 50-1000

\subsubsection{Nuclear Magnetic Resonance (NMR) measurements}

1D- $\left({ }^{1} \mathrm{H}\right.$ and $\left.{ }^{13} \mathrm{C}\right)$ as well as $2 \mathrm{D}-\mathrm{NMR}$ techniques were recorded on an AS 400 Mercury plus spectrometer (Varian, USA). All spectra were determined in $\mathrm{CD}_{3} \mathrm{OD}$ (deuterated methanol) at room temperature and referenced to the solvent signals of $\mathrm{CD}_{3} \mathrm{OD}\left({ }^{1} \mathrm{H}: 4.870 \mathrm{ppm}\right)$ and $\mathrm{CD}_{3} \mathrm{OD}\left({ }^{13} \mathrm{C}: 49.000 \mathrm{ppm}\right)$. MestReNOVA v. 10 (Mestrelab Research, Chemistry Software solutions, USA) was used to process and evaluate the spectra.

\subsubsection{Antidiabetic study}

Male Wistar rats ( $n=5$ per group) were induced with diabetes using $160 \mathrm{mg} / \mathrm{kg}$ alloxan monohydrate [15]. Diabetes was confirmed in rats with FBS of $\geq 120 \mathrm{mg}$ glucose per $100 \mathrm{~mL}$. Diabetic rats were assigned to groups 1-12. Group 1 received Tween $20(5 \mathrm{ml} / \mathrm{kg})$, group 12 glibenclamide $(2 \mathrm{mg} / \mathrm{kg})$ and groups 2-11 received GAF1-GAF10 fractions $(50 \mathrm{mg} / \mathrm{kg}$ ) respectively.

In the antidiabetic study of the subfractions, male Wistar rats were induced with diabetes as described above. Diabetic rats were assigned to seven groups(n=5). Group 1 received Tween-20 $(5 \mathrm{ml} / \mathrm{kg})$, group 7 glibenclamide $(2 \mathrm{mg} / \mathrm{kg})$ and groups 2-6 received GAF7.1, GAF7.2, GAF7.3, GAF7.4 and GAF7.5 $(10 \mathrm{mg} / \mathrm{kg})$ respectively

\subsubsection{Statistical analysis}

Data was expressed as mean \pm standard deviation (S.D.) and analyzed for ANOVA using post doc Duncan multiple range tests. Difference in FBS reduction was considered significant at $p<0.05$ levels. 
Acknowledgements: Mr.Alfred Ozioko, a plant taxonomist, for identification of the plant, Tertiary Education Trust Fund (TETFund) of the Nigerian government provided partial funding for the work, the IPMC University of Munster, Germany provided facilities for characterization of the active compound.

Author contributions: Concept - I.A., A.A.; Design - I.A., A.A., N.U.; Supervision - I.A., A.A.; Resources - N.U.; Materials - N.U.; Data Collection and/or Processing - N.U., C.N.; Analysis and/or Interpretation - N.U., C.N., A.A., I.A.; Literature Search - N.U., C.N.; Writing - N.U.; Critical Reviews - I.A., N.U., A.A., C.N.

Conflict of interest statement: The authors declared no conflict of interest.

Ethics committee approval:Experimental protocols were approved by College of Veterinary Medicine, Michael Okpara University of Agriculture, Umudike Ethics Committee on June 022020 with approval number of MOUAU/CVM/REC/202011.

\section{REFERENCES}

[1] International Diabetes Federation. IDF Diabetes Atlas, 8th ed. Brussels, Belgium: International Diabetes Federation; 2017.

[2] International Diabetes Federation. IDF Diabetes Atlas, 7th ed. Brussels, Belgium: International Diabetes Federation; 2015.

[3] Patterson CC, Dahlquist GG, Gyürü E, Green A, Soltesz G. EURODIAB Study Group. Incidence trends for childhood type 1 diabetes in Europe during 1989-2003 and predicted new cases 2005-20: a multicentre prospective registration study. Lancet. 2009; 373(9680): 2027-2033.

[4] Saeedi P, Petersohn I, Salpea P, Malanda B, Karuranga S, Unwin N, ColagiuriS, Guariguata L, Motala AA, Ogurtsova K, Shaw JE, Bright D, Williams R, on behalf of the IDF diabetes atlas Committee. Global and regional diabetes prevalence estimates for 2019 and projections for 2030 and 2045: Results from the International Diabetes Federation Diabetes Atlas, 9th edition. Diabetes Res Clin Practice. 2019; 157: 107843. [CrossRef]

[5] Asgary S, Rafieian-Kopaei M, Shamsi F, Najafi S, Sahebkar A. Biochemical and histopathological study of the antihyperglycamic and anti-hyperlipidemic effects of cornelian cherry (Cornusmas L.) in alloxan-induced diabetic rats. J Complement Integr Med. 2014; 11(2): 63-69. [CrossRef]

[6] Khatik GL, ADatusalia AK, Ahsan W, Kaur P, Vyas M, Mittaland A, Nayak SK. A retrospective study on thiazole derivatives as the potential antidiabetic agents in drug discovery and development. Curr Drug Discov Technol. 2018;15(3): 163-177. [CrossRef]

[7] Uzor PF, Nnadi CO, Ahiabuike JE, Ani HN. Antidiabeticstudies and dereplication of the bioactive constituents of Anthocleistanobilis G. Don by UHPLC/ESI-QTOF-MS.Dhaka Univ J Pharm Sci.2018; 17(1):19-26.[CrossRef]

[8] Iwu MM, Handbook of African Medicinal Plants, second ed., Taylor and Francis, Boca Raton Florida 2010, pp. 224226.

[9] Okafor JC, Conservation and use of traditional vegetables from woody forest species in Southeastern Nigeria, in: Proceedings of The IPGRI International Workshop on Genetic Resources of Traditional Vegetables in Africa: Conservadtion and Use -1995 Conference (Ed. L. Guarino), Nairobi, Kenya: ICRAF, 29th-31st August,1997, pp. 3138.

[10] Udeh NE, Anaga AO, Asuzu IU. Fasting blood sugar and clinical biochemistry profiles of diabetic rats treated with methanol extract of Gnetumafricanum Welw.Indian JTrad Knowl. 2018; 17(3): 445-450.

[11] Udeh NE, Anaga AO, Asuzu IU. Protective effect of Gnetum africanum methanol leaf extract on pancreatic islets cells in rats. Comp ClinPathol. 2018; 27(3): 649-654. [CrossRef]

[12] Udeh NE, Anaga AO, Asuzu IU. Acute and sub-chronic oral toxicity studies on the methanol leaf extract of Gnetumafricanum Welw in wistar rats. Am J Res Med Sci. 2018; 3(1): 7-14. [CrossRef]

[13] Iweala EEJ, Uhegbu FD, Obidoa O. Biochemical and histological changes associated with long term consumption of Gnetum africanum Welw leaves in rats. Asian J Biochem. 2009; 4(4): 125-132. [CrossRef]

[14] OgbonnayaEC, ChinedumEK. Health promoting compounds and in vitro antioxidant activity of raw and decoctions of Gnetum africanum welw, Asian Pac J Trop Dis. 2013; 3(6): 472-479. [CrossRef]

[15] Ilodibia CV, Ugwu RU, Nwokolo OL, Chukwuma MU, Akachukwu EE. Phytochemical screening, antifungal and antibacterial activity of aqueous and ethanolic leaf and stem extracts of Gnetum africanum Welw. Res J Med Plants. 2015; 9(6): 275-283. [CrossRef] 
[16] Qi SH, Wu DG, Ma YB, Luo XD. A novel flavane from Carapaguianensis. Acta Bot Sin. 2003; 45(9): 1129 - 1133

[17] Spiegler V, Sendker J, Petereit F, Ziebau E, Hensel A. A bioassay guided fractionation of a leaf extract from Combretummucronatum with anthelmintic activity: Oligometricprocyanidins as the active principle. Molecules. 2015; 20(8):14810-14832.[CrossRef]

[18] Pizzolatti MG, Venson AF, Smania AJ, Smania EF, Braz-Filho R. Two epimeric flavalignans from Trichiliacontigua (Meliaceae) antiimicrobial activity. Zeitschr Naturforsch. 2002; 57(5-6): 483-488.[CrossRef]

[19] Fan P, Lou H, Yu W, Ren D, Ma B, Ji M. Novel flavanol derivatives from grape seeds, Tetrahedron Lett. 2004; 45(15): 3163-3166.

[20] Usman A, Thoss V,Itodo AU. Isolation of catechin from Trichiliaemetica whole seeds.Int JSci Global Sustain. 2016; 2(2): 81-85.

[21] Babatunde SB, Moyinoluwa OO, Oluwatosin A, Eigege W, Shreyans JK. Bioguidedisolation of an antioxidant compound from Combretumracemosum P Beave leaf.Int J Biol Chem. 2014; 8(5): 2339-2346. [CrossRef]

[22] Massini L, Rico D, Martin-Diana AB, Barry-Ryan C. Study of antioxidant properties of fractionated apple peel phenolics using a multiple assay approach. Int Food ResJ. 2016; 23(5): 1996-2005.

[23] Aminudin NI, Ahmad F, Taher M, Zulkifli M. Cytotoxic and antibacterial activities of constituents from Calophyllumferrugineum Ridley, Rec Nat Prod. 2016; 10(5): 649-653.

[24] Murni NS, Qamar UA, Alhassan MA, Suganya M, Vikneswari P. Antioxidant and antidiabetic effects of flavonoids: A structure-activity relationship based study. BioMed Res Int. 2017(2017): 1-14.[CrossRef]

[25] Soumyanath A, Traditional Medicines for Modern Times - Antidiabetic Plants, first ed., CRC Press, Boca Raton (FL) 2006.

[26] Mohan S, Nandhakumar L. Role of various flavonoids: Hypotheses on novel approach to treat diabetes. J Med Hypotheses and Ideas.2013; 8(1): 1-6. [CrossRef]

[27] Jiang ZJ, Xu SQ, Xing YU, Hu XM, Pan HY. Effects of flavonoids in Morusindica on blood lipids and glucose in hyperlipidemia-diabetic rats. Chin Herb Med. 2012; 4(4):314-318.[CrossRef]

[28] Jung MM, Park HC, Lee YH, Kang ES, Kim SK. Antidiabetic agents from medicinal plants. Curr Med Chem. 2006; 13(10): 1203-1218. [CrossRef]

[29] Subramanian S. Epicatechin as an anti- diabetic drug. Indian Drugs. 1981; 18: 259-261.

[30] Gutiérrez-Salmeán G, Meaney E, Lanaspa MA, Cicerchi C, Johnson RJ, Dugar S, Pam T, Ramírez-Sánchez I, Villarreal F, Schreiner G, Ceballos G.A randomized placebo-controlled, double-blind study on the effects of (-)epicatechin on the triglyceride/HDLC ratio and cardiometabolic profile of subjects with hypertriglyceridemia: Unique in vitro effects.Int J Cardiol. 2016; 223:500-506. [CrossRef]

[31] Ezuruike UF, Prieto JM. The use of plants in the traditional management of diabetes in Nigeria: Phamacological and toxicological considerations. J Ethnopharmacol. 2014; 155(2): 857- 924. [CrossRef]

[32] Trease GE, Evans WC. Pharmacognosy. 13 th edition, BailliereTindall, London 1996, pp. 89-122, 313-544.

This is an open access article which is publicly available on our journal's website under Institutional Repository at http://dspace.marmara.edu.tr. 